\title{
PENGARUH MODEL PEMBELAJARAN DISCOVERY LEARNING TERHADAP HASIL BELAJAR SISWA TEMA PRAJA MUDA KARANA DI KELAS III SD NEGERI 105327 PERDAMEAN
}

\author{
Angel A Marbun, Anton Sitepu, Juliana
}

Surel: angelmarbun17@gmail.com,

\begin{abstract}
This study aims to determine the effect of the discovery learning model on student learning outcomes on the praja Muda Karana theme which was carried out in class III of SD Negeri 105327 Perdamean for the 2020/2021 academic year. There are 60 students in the class, all of them are in the third grade. Saturated sampling was used to collect samples from up to 60 students, who were divided into two groups of 30 and 30 students, respectively. An experimental approach was used in this investigation. The results of statistical analysis showed that the learning outcomes in the experimental class using the Discovery Learning model were in the good category, with an average of 83.2. Meanwhile, without using the control class learning model, learning outcomes were not significantly different from the KKM which was set at an average of 65.3. Because tcount > ttable, $H o$ is rejected and Ha is accepted by $t$-test, the value of tcount $=5.976$ while t-table is 1.697. This shows that the discovery learning model has a significant effect on the learning outcomes of third grade students of SD Negeri 105327 Perdamean for the 2020/2021 academic year.
\end{abstract}

Keywords: Learning Outcomes, Young Praja Karana, Discovery Learning Model

\begin{abstract}
ABSTRAK
Penelitian ini bertujuan untuk mengetahui pengaruh model discovery Learning terhadap hasil belajar siswa pada tema praja muda karana yang dilakukan di kelas III SD Negeri 105327 Perdamean tahun pembelajaran 2020/2021. Ada 60 siswa di kelas, semuanya berada di kelas tiga. Pengambilan sampel jenuh digunakan untuk mengumpulkan sampel dari hingga 60 siswa, yang dibagi menjadi dua kelompok yang masing-masing terdiri dari 30 dan 30 siswa. Pendekatan eksperimental digunakan dalam penyelidikan ini. Hasil analisis statistik menunjukkan bahwa hasil belajar pada kelas eksperimen yang menggunakan model Discovery Learning berada pada kategori baik, dengan rata-rata 83,2. Sedangkan tanpa menggunakan model pembelajaran kelas kontrol, hasil belajar tidak berbeda signifikan dengan KKM yang ditetapkan rata-rata 65,3. Karena $t_{\text {hitung }}>t_{\text {tabel }}$ maka Ho ditolak dan Ha diterima dengan uji $t$, nilai $t_{\text {hitung }}=5,976$ sedangkan $t_{\text {tabel }}$ 1,697. Hal ini menunjukkan bahwa model discovery learning berpengaruh signifikan terhadap hasil belajar siswa kelas III SD Negeri 105327 Perdamean Tahun Pelajaran 2020/2021.
\end{abstract}

Kata Kunci: Hasil Belajar, Praja Muda Karana, Model Discovery Learning 



\section{PENDAHULUAN}

Pendidikan dapat diartikan sebagai kegiatan seseorang dalam membimbing dan mengajari anak menuju ke pertumbuhan dan perkembangan secara optimal agar dapat berdiri sendiri dan bertanggung jawab. Pendidikan idealnya tidak hanya berorientasi pada masa lalu dan masa kini, tetapi merupakan proses yang mengantisipasi dan membicarakan masa depan agar sejalan dengan situasi yang sedang terjadi di masyarakat. Tujuan pendidikan untuk menghantarkan manusia menuju alam kedewasaan yang sempurna lewat proses yang direncanakan dan diingikan baik oleh dirinya maupun oleh masyarakat yang ada di sekelilingnya. Akan tetapi pendidikan di Indonesia dihadapkan pada beberapa hal diantaranya. Masalah pemerataan pendidikan, masalah mutu pendidikan, masalah relevansi dan masalah sfisiensi serta efektivitas (Tanjung 2016:70).

Pendidikan di sekolah dasar adalah landasan awal untuk menanamkan konsep yang benar pada siswa, itu adalah tingkat pendidikan yang sangat penting yang membentuk kepribadian seseorang. Guru adalah pendidik profesional dengan tugas utama mendidik, mengajar, melatih dan mengevaluasi siswa pada pendidikan anak usia dini jalur pendidikan formal, pendidikan dasar dan pendidikan menengah. Hal tersebut sejalan dengan undangundang RI No. 20 tahun 2003 tentang sistem pendidikan nasional dijabarkan kembali pada sejumlah peraturan, diantaranya peraturan No.19 Tahun 2005 tentang standar pendidikan nasional. Kurikulum yang diterapkan di Indonesia adalah kurikulum 2013 yang sejalan dengan peraturan yang sudah ditetapkan. Kurikulum 2013 (K-13), merupakan kurikulum yang menyempurnakan pola pembelajaran yang berpusat pada guru menjadi pola pembelajaran yang berpusat pada peserta didik. Salah satu model pembelajaran yang mampu mengembangkan peran guru sebagai pembimbing dan fasilitator yang baik untuk mengembangkan potensi siswa yaitu model pembelajaran Discovery Learning. Model. pembelajaran Discovery Learning atau model pengorganisasian materi yang terintegrasi dipadukan oleh suatu tema.

Hasil belajar merupakan suatu pernyataan yang spesifik yang dinyatakan dalam perilaku dan penampilan yang diwujudkan dalam bentuk tulisan untukmenggambarkan hasil belajar yang diharapkan. Berdasarkan hasil pengamatan peneliti yang dilakukan pada saat magang III kelas III SD Negeri 105327 Perdamean kec. Tanjung Morawa, bahwa sekolah sudah mengikuti pembelajaran tematik, akan tetapi dalam penerapannya masih belum optimal. Metode pembelajaran guru masih tradisional, dan guru belum sepenuhnya menemukan discovery learning, yaitu suatu paradigma pembelajaran dimana siswa mengkonstruksi pengetahuannya sendiri dengan melakukan percobaan dan 
Angel A Marbun, Anton Sitepu, Juliana : Pengaruh Model ...

menyimpulkan suatu prinsip dari hasil.Pembelajaran tematik adalah salah satu bentuk atau model dari pembelajaran terpadu. Yang pada intinya menekankan pada pola melaksanakan pembelajaran secara aktif dan kreatif dalam melibatkan siswa. Selain itu, dalam proses pembelajaran kebanyakan guru hanya terpaku pada buku teks sebagai satusatunya sumber belajar mengajar. Hal ini menyebabkan siswa kurang bersemangat dan kurang aktif dalam mengikuti pembelajaran, yang menyebabkan rendahnya hasil belajar siswa.

Penelitian sebelumnya yang dilakukan oleh Putri, dkk (2017:5) yang berjudul Pengaruh Model pembelajaran Discovery Learning Terhadap Hasil Belajar Tematik Siswa Kelas IV SD Negeri 55 Pontianak bahwa dalam sekolah dasar guru harus kreatif dalam memilih model pembelajaran. Hasil dari penelitian ini menunjukkan bahwa hasil belajar siswa kelas eksperimen sudah lebih baik dari hasil belajar awal siswa dan mengalami peningkatan dikarenakan kelas eksperimen telah diberi perlakuan dengan menggunakan model pembelajaran Discovery Learning.

\section{METODE PENELITIAN}

Penelitian ini menggunakan metode eksperimen, dengan cara langsung ke sekolah untuk memperoleh data- data yang dibutuhkan untuk melihat pengaruh model pembelajaran Discovery Learning terhadap hasil belajar. populasi dalam penelitian adalah seluruh siswa kelas III SD yang terdiri dari dua kelas yaitu III A (30 siswa) dan III B (30 siswa) sehingga jumlah seluruh kelas III adalah 60 siswa. Untuk memperoleh data yang diperlukan diberikan post test berjumlah 35 soal kepada siswa kelas III SD Negeri 105327 Perdamean Kec. Tanjung Morawa Tahun Pembelajaran 2020/2021

\section{HASIL PENELITIAN DAN PEMBAHASAN}

Untuk mengetahui kemampuan awal siswa penelitian ini menggunakan Adapun tujuan dilakukannya penelitian ini adalah untuk Mengetahui proses dan hasil serta pengaruh model Pembelajaran Discovery Learning terhadap Hasil Belajar Tema Praja Muda Karana Siswa di Kelas III SD Negeri 105327 Perdamean Kec. Tanjung Morawa Tahun Pembelajaran 2020/2021. Pretest di kelas eksperimen dan kelas kontrol dengan jumlah soal masing 35 butir soal pilihan berganda, pre-test eksperimen dengan rata-rata 57,86 dan pre-test kontrol 57,1 . Dari ratarata tersebut dapat dilihat bahwa kemampuan pre- test dikelas eksperimen dan kelas kontrol masih dibawah KKM atau masih rendah. Kemudian setelah diberikan perlakuan model pembelajaran Discovery Learning dikelas eksperimen memiliki rata- rata 83,2, sementara di kelas kontrol dengan model konvensional memiliki nilai rata-rata 65,3 . 


\section{Pembahasan}

Tabel 1. Distribusi Frekuensi Data kelas Eksperimen Model pembelajaran Discovery Learning.

\begin{tabular}{r|r|r|r|r|r}
\hline \multicolumn{1}{r|}{$\mathbf{X}$} & \multicolumn{1}{|c|}{$\mathbf{F X}$} & $\mathbf{X}=\mathbf{X}-\overline{\boldsymbol{X}}$ & $\mathbf{X}^{\mathbf{2}}$ & \multicolumn{1}{c}{$\mathbf{\mathbf { X }}$} \\
& & & & & $\mathbf{2}$ \\
\hline 54 & 1 & 54 & $-29,2$ & 852,64 & 852,64 \\
\hline 60 & 1 & 60 & $-23,2$ & 538,24 & 538,24 \\
\hline 65 & 1 & 65 & $-18,2$ & 331,24 & 331,24 \\
\hline 68 & 2 & 136 & $-15,2$ & 231,04 & 462,08 \\
\hline 74 & 2 & 148 & $-9,2$ & 84,64 & 169,28 \\
\hline 77 & 3 & 231 & $-6,2$ & 38,44 & 115,32 \\
\hline 80 & 3 & 240 & $-3,2$ & 10,24 & 30,72 \\
\hline 82 & 2 & 164 & $-1,2$ & 1,44 & 2,88 \\
\hline 85 & 4 & 340 & 1,8 & 3,24 & 12,96 \\
\hline 91 & 1 & 91 & 7,8 & 60,84 & 60,84 \\
\hline 94 & 3 & 282 & 10,8 & 116,64 & 349,92 \\
\hline 97 & 5 & 485 & 13,8 & 190,44 & 952,2 \\
\hline 100 & 2 & 200 & 16,8 & 282,24 & 564,48 \\
\hline & 30 & $\sum F x 2496$ & & & $\sum F X 2$ \\
& & & & & 4442,8 \\
\hline & & 83,2 & & & \\
\hline
\end{tabular}

Berdasarkan hasil dari perhitungan yang diperoleh dari kelas eksperimen, maka dapat disimpulkan bahwa nilai rata-rata (mean) adalah 83,2 sedangkan untuk hasil standar deviasinya adalah 12,16 dan untuk standar error adalah 2,260. Pada tahap pelaksanaan penelitian di kelas eksperimen diberikan pre-test dan post-test yang dimana merupakan salah satu syarat awal penelitian yang bertujuan untuk melihat kemampuan akhir belajar siswa setelah pemberian model pembelajaran Discovery Learning. Hasil dari penelitian ini rata-rata pada post-test sekitar 83,2. Dapat dilihat perbandingan nilai tersebut melalui diagram batang yang dimana nilai post-test lebih tinggi dibandingkan dengan pre-test. 
Angel A Marbun, Anton Sitepu, Juliana : Pengaruh Model ...

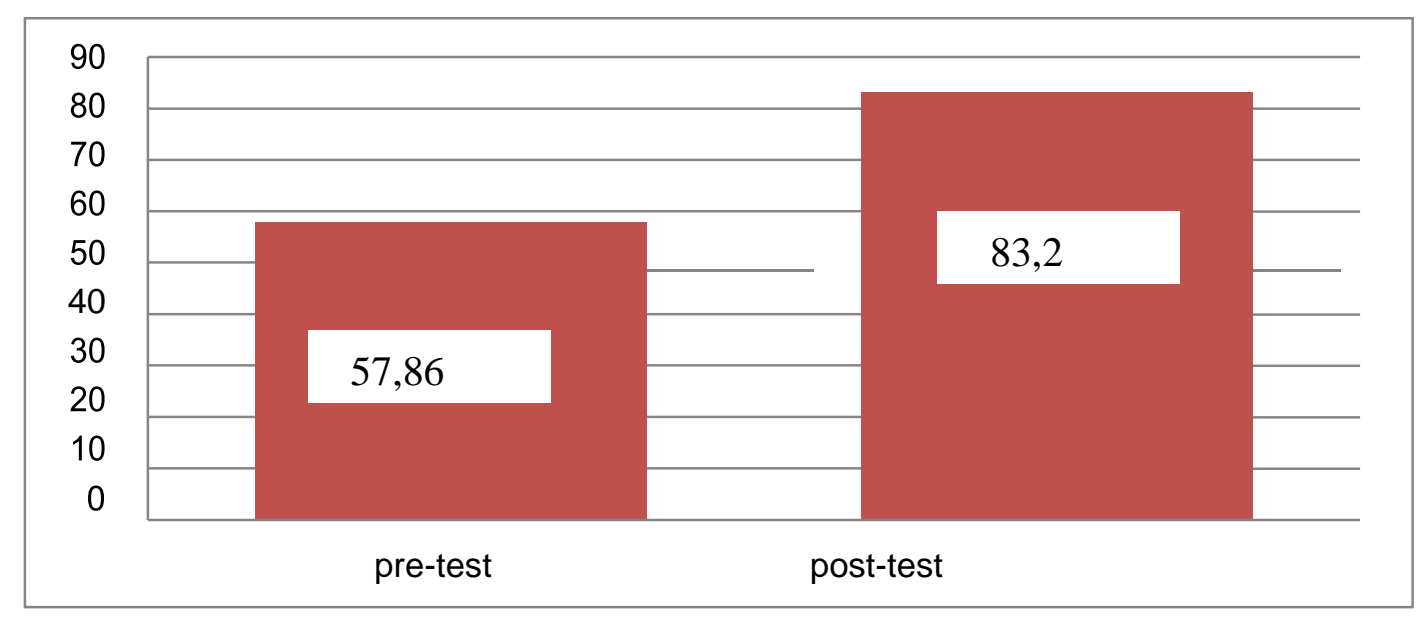

Gambar 1. Diagram data nilai Pre-test dan Post-test kelas eksperimen

Tabel 2. Distribusi Frekuensi Data Kelas Kontrol Model konvensional

\begin{tabular}{r|r|r|r|r|r}
\hline \multicolumn{1}{c|}{ X } & \multicolumn{1}{c|}{$\mathrm{FX}$} & $\mathrm{X}=\mathrm{X}-\bar{X}$ & \multicolumn{1}{c|}{$\mathrm{X}^{2}$} & \multicolumn{1}{c}{$\mathrm{FX}^{2}$} \\
\hline 45 & 1 & 45 & $-20,3$ & 412,09 & 412,09 \\
\hline 48 & 1 & 48 & $-17,3$ & 299,29 & 299,29 \\
\hline 51 & 1 & 51 & $-14,3$ & 204,49 & 204,49 \\
\hline 54 & 2 & 108 & $-11,3$ & 127,69 & 255,38 \\
\hline 60 & 5 & 300 & $-5,3$ & 28,09 & 140,45 \\
\hline 62 & 5 & 310 & $-3,3$ & 10,89 & 54,45 \\
\hline 65 & 4 & 260 & $-0,3$ & 0,09 & 0,36 \\
\hline 68 & 3 & 204 & 2,7 & 7,29 & 21,87 \\
\hline 71 & 1 & 71 & 5,7 & 32,49 & 32,49 \\
\hline 74 & 2 & 148 & 8,7 & 75,69 & 151,38 \\
\hline 77 & 1 & 77 & 11,7 & 136,89 & 136,89 \\
\hline 80 & 3 & 240 & 14,7 & 216,09 & 648,27 \\
\hline 97 & 1 & 97 & 31,7 & 1004,89 & 1004,89 \\
\hline & 30 & $\sum F x 1959$ & & & \multirow{2}{*}{$F^{2} 3362,3$} \\
\hline & & 65,3 & & & \\
\hline
\end{tabular}

Berdasarkan hasil dari perhitungan yang diperoleh dari kontrol, maka dapat disimpulkan bahwa nilai rata-rata (mean) adalah 65,3 sedangkan untuk hasil standar deviasinya adalah 10,58 dan untuk standar error adalah 1.966. Pada tahap pelaksanaan penelitian di kelas kontrol diberikan pre-test dan posttest yang dimana merupakan salah satu syarat awal penelitian yang bertujuan untuk melihat kemampuan akhir belajar siswa dengan pembelajaran konvensional. Hasil dari 
penelitian ini rata-rata pada pre- test tersebut adalah 57,1 dan nilai rata-rata pada post-test adalah 65,3. Maka dapat dilihat perbandingan nilai tersebut melalui diagram batang yang dimana nilai post-test lebih tinggi dibandingkan dengan pre-test.

Gambar 2. Diagram nilai Pre-test dan post-test kelas kontrol

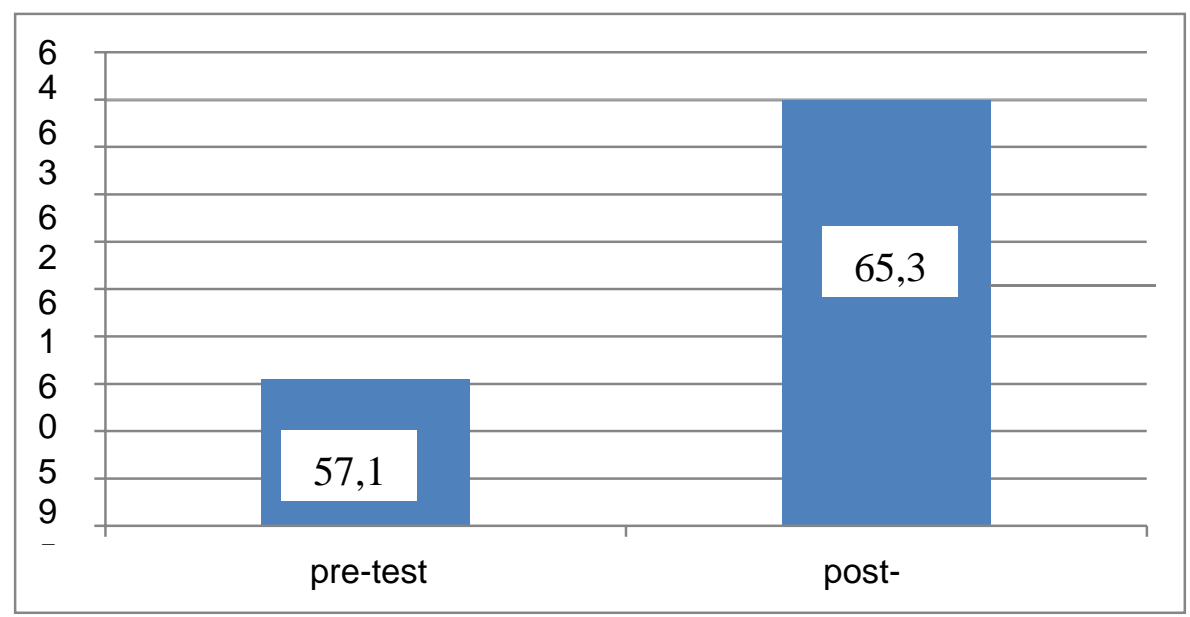

Selanjutnya dilakukan uji normalitas untuk mengetahui apakah dalam penelitian tersebut berdistribusi normal atau tidak. Setelah dilakukan perhitungan dengan menggunakan SPSS pengujian normalitas yaitu dengan menggunakan uji
Kolmogorov-Smirnov (K-S), diketahui nilai signifikan kelas eksperimen 0,127>0,05 dan kelas kontrol $0.110>0,05$ maka dapat disimpulkan bahwa data berdistribusi normal.

Tabel 3. Uji Normalitas

\begin{tabular}{ll|r|r}
\hline & & eksperimen & Kontrol \\
\hline $\mathrm{N}$ & & 30 & 30 \\
Normal Parametersa,b & Mean & 83.20 & 65.30 \\
& Std. Deviation & 12.377 & 10.768 \\
Most Extreme Differences & Absolute & .142 & .145 \\
& Positive & .087 & .144 \\
Test Statistic & Negative & -.142 & -.145 \\
Asymp. Sig. (2-tailed) & & .142 & .145 \\
\hline
\end{tabular}


Angel A Marbun, Anton Sitepu, Juliana : Pengaruh Model ...

Kemudian untuk melihat diketahui nilai signifikansi 0,260 > apakah data berdistribusi homogen, 0,05. Maka dapat disimpulkan data peneliti melakukan uji homogenitas. tersebut berdistribusi homogeni Dengan menggunakan SPSS dapat

Tabel 4. Test of Homogeneity of Variance

\begin{tabular}{l|l|r|r|r|c}
\hline \multicolumn{2}{l}{} & $\begin{array}{r}\text { Levene } \\
\text { Statistic }\end{array}$ & $\begin{array}{c}\text { df } \\
1\end{array}$ & $\begin{array}{c}\text { df } \\
2\end{array}$ & Sig. \\
\hline HASIL & Based on Mean & 1.294 & 1 & 58 & .260 \\
\hline
\end{tabular}

Berdasarkan hasil uji hipotesis menunjukkan bahwa dapat diketahui bahwa nilai thitung > ttabel 5,976> 1.697 yang artinya terdapat pengaruh yang signifikan dengan menggunakan model pembelajaran Discovery Learning terhadap hasil belajar siswa dengan tema praja muda karana pada

\section{SIMPULAN}

Berdasarkan hasil analisis data pengujian hipotesis serta pembagian, maka dapat ditarik kesimpulan sebagai berikut:

- Nilai rata-rata hasil belajar pada tema 8 subtema 1 pembelajaran 4 siswa kelas III SD Negeri Perdamean Kec. Tanjung Morawa Tahun pembelajaran 2020/2021 tanpa menggunakan model pembelajaran Discovery Learning adalah 64,86 berada dalam kategori cukup.

- Nilai rata-rata hasil belajar pada tema 8 subtema 1 pembelajaran 4 di kelas III SD Negeri 105327 Perdamean Kec. Tanjung morawa tahun pembelajaran 2020/2021. Hasil perhitungan uji hipotesis tersebut menggunakan program SPSS ver 22.00. pembelajaran 4 siswa kelas III SD Negeri 105327 Perdamean Kec.Tanjung Morawa tahun pembelajaran 2020/2021 adalah 83,2 berada dalam kategori sangat baik.

- Hasil belajar siswa dengan menggunakan pada model pembelajaran Discovery Learning yang berpengaruh signifikan terhadap hasil belajar. Berdasarkan hasil uji hipotesis maka disimpulkan bahwa thitung diperoleh lebih besar dari ttabel yaitu 5,976>1,697 artinya hipotesis nilai $\left(\mathrm{Ho}_{\mathrm{O}}\right)$ ditolak dan hipotesis alternatif $\left(\mathrm{H}_{\mathrm{a}}\right)$ diterima.

\section{DAFTAR RUJUKAN}

Anzelina, D., \& Zai, E. 2020. Penerapan Model Problem Based Learning Untuk Meningkatkan Hasil Belajar Tema Indahnya Kebersamaan Di kelas IV. Jurnal Education FKIP UNMA, 6 (2), 344-349.

Arikunto, S. 2018. Prosedur 
Pebelitian Suatu Pendekatan

Pratik. Jakarta: Rineka Cipta.

Aunurrahman. 2014. Belajar dan

Pembelajaran (9th ed.).

Bandung: Alfabeta.

Darmadi, H. 2014. metode Penelitian

Pendidikan dan Sosial.

Bandung: Alfabeta.

Dimyati, \& Mudjiono. 2015. Belajar

\& Pembelajaran (5th ed.).

Jakarta: Rineka Cipta.

Fitriyah, F., Murtadlo, A., \& Warti,R.

2017. Pengaruh Model

Pembelajaran Discovery

Learning terhadap Hasil

Belajar Matematika Siswa MAN

Model Kota Jambi. Jurnal

Pelangi, 9(2), 108-112.

Istarani. 2017. 58 Model

Pembelajaran Inovatif. Medan:

Media Persada.

Istarani, \& Pulungan, I. 2018. Ensiklopedi Pendidikan (1st ed.). Medan: Media Persada.

Jihad, A., \& Haris, A. 2012. evaluasi pembelajaran (I). Yogyakarta: Multi Pressindo.

Khairani, makmun. 2017. Psikologi Belajar. Yogyakarta: Aswaja Pressindo.

Kodir, A. 2018. Manajemen Pembelajaran Saintifik kurikulum 2013 Pembelajaran Berpusat Pada Siswa. Bandung: Pustaka Setia.

Kristin, F., \& Rahayu, D. 2016. Pengaruh Penerapan Model Pembelajaran Discovery Learning Terhadap Hasil Belajar Ips Pada Siswa Kelas 4 SD. Scholaria: Jurnal Pendidikan Dan Kebudayaan,
$6(1), 84$.

Kurniawan, D. 2014. Pembelajaran Terpadu Tematik (Teori, Praktik, dan Penilaian). Bandung: Alfabeta.

Lestari, E. 2020. Model Pembelajaran Discovery Learning di Sekolah Dasar. Yogyakarta: Budi Utama.

Lubis, A. 2015. Strategi Belajar Mengajar. Medan: Perdana Publising.

Manullang, M., \& Pakpahan, M. 2014. Metodologi Penelitian Proses Penelitian Praktis. Medan: Citapustaka Media.

Patandung, Y. 2017. Pengaruh model discovery learning terhadap peningkatan motivasi belajar IPA Siswa. Journal of Educational Science and Technology (EST), 3(1), 9.

Priansa, D. 2015. Manajemen Peserta Didik dan Model Pembelajaran (1st ed.). Bandung: Alfabeta.

Purwanto. 2011. Evaluasi Hasil Belajar (3rd ed.). Yogyakarta: Pustaka Pelajar.

Putri, R. H., Lesmono, A. D., \& Aristya, P. D. 2017. Pengaruh model discovery learning terhadap hasil belajar. Jurnal Pembelajaran Tematik, 6(2), 168-174.

Putri, R. H., Lesmono, A. D., \& Aristya, P. D. 2017. Pengaruh model discovery learning terhadap hasil belajar. Jurnal Pembelajaran Fisika, 6(2), 168-174.

Sagala, S. 2017. Konsep dan Makna Pembelajaran Untuk Membantu 
Angel A Marbun, Anton Sitepu, Juliana : Pengaruh Model ...

Memecahkan Problematika

Belajar dan Mengajar.

Bandung: Alfabeta.

Slameto. 2017. Belajar dan Faktor-

faktor yang mempengaruhi.

Jakarta: Rineka Cipta.

Sudjana. 2016. Metode Statistika

(Ketujuh). Bandung:

TARSITO.

Sugiyono. 2017. Penelitian

Kombinasi. Bandung: Alfabeta.

Sugiyono. 2010. Metode Penelitian

Kuantitatif Kualitatif dan $R \& D$

(10th ed.). Bandung: Alfabeta.

Tanjung, D. S. 2016. Meningkatkan

Hasil Belajar Ips Siswa Dengan

Menerapkan Model

Pembelajaran Kooperatif Tipe

Team Games Tournament (Tgt)

Di Kelas V Sdn 200111

Padangsidimpuan. Juril Amik

Mbp, Iv(1), 68-79. 